\title{
Self-assessed anaesthesia nursing competence and related factors
}

\author{
Yunsuk Jeon*1,2, Riitta Meretoja ${ }^{1,2}$, Tero Vahlberg ${ }^{3}$, Helena Leino-Kilpi ${ }^{1,4}$ \\ ${ }^{1}$ Department of Nursing Science, University of Turku, Turku, Finland \\ ${ }^{2}$ Joint Authority Administration, Helsinki University Hospital, Helsinki, Finland \\ ${ }^{3}$ Department of Biostatistics, University of Turku, Turku, Finland \\ ${ }^{4}$ Turku University Hospital, Turku, Finland
}

Received: November 26, 2019

DOI: $10.5430 /$ jnep.v10n6p9
Accepted: February 20, 2020

Online Published: February 26, 2020

\begin{abstract}
Objective: Assessing the level of competence of nurses in anaesthesia care is important not only in ensuring the quality of anaesthesia care, but also in developing a competence-based nursing education programme. This study aimed to assess Finnish nurses' competence in anaesthesia nursing and to describe factors associated with it. This study will provide knowledge to support a competence-based education approach to anaesthesia nursing.

Methods: A cross-sectional research design was used. A self-assessment (Anaesthesia Nursing Competence Scale) was developed for this study. The scale (39 items, 7 domains) used a Visual Analogue Scale $(0=$ not competent at all, $100=$ excellent $)$. Data were collected from registered nurses $(n=222)$ in anaesthesia departments at university hospitals in Finland (May-October 2017).

Results: The overall level of anaesthesia nursing competence was self-assessed as good (Mean 88, SD 9.0). Of the seven competence domains, collaboration within patient care was assessed as being the highest and knowledge of anaesthesia patient care the lowest. Longer work experience and completion of specialised anaesthesia nursing education were factors positively associated with anaesthesia nursing competence.

Conclusions: This study suggests that the general nursing education of nurses should provide more opportunities to improve nurses' competence in the theoretical knowledge of anaesthesia. A specialised programme of anaesthesia nursing education at a master's level might be one suggestion to meet the challenges in anaesthesia nursing in Finland. Further studies with different data collection methods such as observation, a knowledge test, or patient interviews would provide a more extensive picture of anaesthesia nursing competence.
\end{abstract}

Key Words: Anaesthesia nursing competence, Anaesthesia nurse, Nurse competence, Competence assessment, Self-assessment, AnestComp

\section{INTRODUCTION}

Over the past two decades, it has been the aim of European nursing education to develop competence-based education and to harmonize the structures of nursing education through several reforms. ${ }^{[1-4]}$ However, despite such efforts, there are still differences in the field of anaesthesia nursing edu- cation as well as general nursing education in Europe. ${ }^{[1,2]}$ In order to practice as nurses in anaesthesia care, some European countries (e.g. France, Iceland, Norway, Sweden, and Switzerland) require nurses to have a post-registration qualification subsequent to their initial general nursing education; after which they are called nurse anaesthetists. ${ }^{[2,5,6]} \mathrm{In}$

\footnotetext{
*Correspondence: Yunsuk Jeon; Email: yunsuk.jeon@utu.fi; Address: Department of Nursing Science, University of Turku, Joukahaisenkatu 3-5, A-wing, 5 F Turku 20014, Finland.
} 
some countries including Finland, general registered nurses have entered into anaesthesia nursing practice without additional education. In Finland, the qualification to be a nurse (3.5 years of full-time study and 210 European Credit Transfer and Accumulation System) is provided at polytechnics (called universities of applied sciences) and is focused on a general registered nurses qualification (Bachelor of Health Care). ${ }^{[2,7]}$ Anaesthesia departments in hospitals have then trained registered nurses through their own orientation programmes for anaesthesia nursing; after which they are called anaesthesia nurses. ${ }^{[2,8,9]}$

The goal of nurse education is to provide an appropriate theoretical and clinical experience to prepare nurses to meet the challenges of clinical practice. ${ }^{[3]}$ It has been discussed that newly graduate registered nurses have very little experience and knowledge of anaesthesia nursing in Finland. ${ }^{[2,8,9]}$ Therefore, a competence assessment of anaesthesia nurses is important to ensure the levels of nurse competence and to identify the fields of educational needs. ${ }^{[10-13]}$ However, competence assessment is very challenging due to the variety of issues that must be considered such as the conceptualisation of competence and psychometric properties (reliabilities and validities) of the measurement. ${ }^{[14-16]}$ One of the difficulties in competence assessment research is the definition of competence because it is defined differently by different occupations. ${ }^{[10,15,16]}$ Based on the competence defined by the International Council of Nurses, ${ }^{[17]}$ anaesthesia nursing competence can be defined as the combination of knowledge, skill, and judgement associated with anaesthesia nursing to perform effectively in the domain of possible encounters: ethics, risk care, technology, collaboration, medication, and anaesthesia nursing intervention. ${ }^{[14,18,19]}$

Previous research assessing competence in anaesthesia nursing has been limited to measuring 1) technical skills being representative of nurse performance in specific scenarios with patient simulators (e.g. bronchospasm, acute haemorrhage, hyperkalaemia), ${ }^{[20-23]} /$ non-technical skills (e.g. leadership, teamwork, and problem-solving) by evaluators' observation, ${ }^{[24]}$ 2) perception of the professional self (professionalism, trait, knowledge, empathy) by self-assessment, ${ }^{[25]}$ or 3) knowledge demonstrated in written examinations (e.g. airway management, pharmacology, physiology). ${ }^{[23]}$ The technical/non-technical skill-related studies have criticised the relationship between competence and performance, the evaluators' reliability, and the limitations of rating scales when measuring multi-dimensional nurse competence. In the studies of the perception of professional self, it is unclear whether the professional self demonstrates competence or not. In the studies regarding written examination, the validity issue of the knowledge test was questioned because a negative correlation between the written examination scores and performance scores were found. Recent research in anaesthesia nursing has become more focused on scale development and validation related to separate non-technical skills. ${ }^{[26,27]}$ However, competence in anaesthesia nursing can be characterised as a holistic conceptualisation including technical/non-technical skills, judgement, as well as theoretical knowledge in anaesthesia care. ${ }^{[17-19,28,29]}$ Thus, there is a preference for using such an integrated concept of competence when assessing nurse competence in anaesthesia nursing.

Empirical studies investigating factors associated with nurse competence in anaesthesia care are scarce. Only two studies were found. ${ }^{[23,25]}$ The first assessing nurse performance in simulation reported that age, length of work experience, practice setting, and prior exposure to simulation had no significant correlations with nurse performance; ${ }^{[23]}$ however, the generalisation of the results of the study was limited due to the small number of the participants $(n=18)$. The second study based on self-assessment $(n=87)^{[25]}$ described that the professional self was positively correlated with age and length of work experience, but not on gender. In the broader nursing profession such as perioperative nursing care, length of work experience and specialty education as post-registration education were related to self-assessed perioperative competence $(n=132) .{ }^{[30-32]}$ However, there is a lack of anaesthesia nursing-specific evidence for identifying factors associated with anaesthesia nursing competence. Since the majority of the competence studies in anaesthesia nursing have been simulation-based studies with a small sample size, it was difficult to use an inferential statistical approach; there seems to be a lack of research on factors associated with competence. Among the assessment methods, self-assessment is considered to be a common approach in terms of time-saving and cost-effectiveness when measuring nurse competence in clinical settings, ${ }^{[6,7,10,15,29,31,33]}$ and also enables a larger sample size to be used than simulationbased studies.

Therefore, the purpose of the study was to assess the anaesthesia nursing competence of anaesthesia nurses based on their self-assessment and to describe the factors associated with anaesthesia nursing competence. Competence assessment of anaesthesia nurses is a critical issue not only for the quality of anaesthesia care and patient safety, but also as a means of observing the outcomes of anaesthesia nursing education. The results will produce new knowledge to support a competence-based educational approach both in general nursing education and post-registration education for anaesthesia nursing. 
The research questions were:

1) What is the level of anaesthesia nursing competence of nurses based on self-assessment?

2) What factors are associated with the anaesthesia nursing competence?

\section{METHODS}

\subsection{Instrument-anaesthesia nursing competence scale}

An Anaesthesia Nursing Competence Scale (AnestComp) was developed for this study because there was a lack of selfassessment instruments specifically measuring anaesthesia nursing competence. The theoretical structure and content of the scale were based on literature reviews ${ }^{[2,18]}$ and a Delphi study seeking the competence domains of anaesthesia nursing. ${ }^{[19]}$ Experts confirmed the face validity and content validity of the scale. The AnestComp was comprised of seven domains: ethics of anaesthesia care (5 items), patient risk care (5 items), patient engagement with technology (5 items), collaboration within patient care (5 items), anaesthesia patient care with medication (5 items), peri-anaesthesia nursing intervention (9 items), and knowledge of anaesthesia patient care (5 items). The scale was designed for participants to self-assess their level of competence in these 39 items by using a Visual Analogue Scale (VAS 0-100 mm); the VAS ranged from 0 (not competent at all) to 100 (excellent competence). To examine the feasibility of the scale, the electronic form of AnestComp was pre-tested with 32 anaesthesia nurses practicing in anaesthesia departments in a University hospital in Finland; item mean values on the VAS ranged from 73.0-97.8 and Cronbach's $\alpha$ for sum variables indicated acceptable internal consistency: ethics of anaesthesia care (0.89), patient risk care (0.90), patient engagement with technology (0.70), collaboration within patient care (0.62), anaesthesia patient care with medication (0.83), perianaesthesia nursing intervention (0.91), and knowledge of anaesthesia patient care $(0.84) .{ }^{[19]}$

\subsection{Data collection}

A convenience sample of anaesthesia nurses $(\mathrm{N}=431)$ were contacted between May and October in 2017. In this study, anaesthesia nurses refer to registered nurses who were trained for anaesthesia nursing through orientation programmes organised by anaesthesia departments in local hospitals in Finland. Anaesthesia nurses practicing in ORs and recovery rooms of all specialities in two of the five Finnish university hospitals were invited. Emails with the internet link for the survey (Webropol 2.0) were sent to nurse managers of the 14 operation units in the two University hospitals. After two of reminders had been sent, $31 \%(n=132)$ of the target group replied. In order to increase the response rate, a paper and pencil version of the survey was prepared and those who did not respond via the electronic survey were allowed to participate in the paper and pencil survey. The response rate then increased to $52 \%(\mathrm{n}=222)$.

\subsection{Ethical considerations}

Ethical principles were followed as stated by the World Medication Association ${ }^{[34]}$ and ethical approval was granted by the ethics committee of the University (Statement 25/2017, 3rd of May 2017) in Finland. Research permissions to collect nurses' data for the electronic survey was obtained from the two University hospitals in April 2017 (235/2017 26th of April 2017 and 005/17 27th of April 2017 respectively). Additional research permissions for a paper and pencil survey were confirmed by each University hospital in September 2017. In this study, returning the electronic/paper and pencil questionnaire was regarded as consent to participate in the survey.

\subsection{Data analysis}

IBM SPSS Statistics for Windows version 22.0 was used (IBM Corp., Armonk, NY). Sample characteristics and sum variables were summarised by descriptive statistics. In the study, correlations between anaesthesia nursing competence and background factors were calculated by Pearson's correlation coefficients: age and length of work experience. The mean differences between two groups were calculated by two independent sample T-tests: gender and completion of specialised anaesthesia nursing education. In order to compare more than two groups, one-way analyses of variance (ANOVA) with post hoc Tukey HSD test were used: groups categorised by length of work experience, educational degree level, continuing education level, and roles of perioperative nurses. Because the distribution of the data was slightly skewed, the results from the parametric tests were confirmed by non-parametric methods (Mann-Whitney U-test and Kruskall-Wallis test).

Multiple regression helps to understand how strongly factors contribute to explaining the anaesthesia nursing competence. ${ }^{[35,36]}$ The final regression model included only the variable significantly associated with anaesthesia nursing competence. Age was excluded from the final model due to the high correlation with work experience to avoid multicollinearity problems. A statistically significant level was considered to be $p \leq .05$.

In this study, the high values of Cronbach's $\alpha$ across the seven subscales is considered to indicate good reliability: ethics of anaesthesia care (0.84), patient risk care (0.94), patient engagement with technology (0.85), collaboration within patient care (0.83), anaesthesia patient care with medication (0.93), peri-anaesthesia nursing intervention (0.95), 
and knowledge of anaesthesia patient care (0.88). The validity was confirmed by several construct validity tests (confirmatory factor analysis, exploratory factor analysis, and known-group technique); the psychometric properties of the AnestComp have been reported in a separate article. ${ }^{[19]}$

\section{RESULTS}

\subsection{Sample and description of data}

The sample consisted of 222 anaesthesia nurses. The mean age was 42 years $(S D=10.01)$ and the length of work experience in anaesthesia nursing was 13 years $(\mathrm{SD}=9.63$ ) (see Table 1). The mean duration of orientation for anaesthesia nursing was 3 months ( $\mathrm{SD}=3.83)$. Most participants $(94 \%, \mathrm{n}$ $=209)$ had a bachelor's degree and $6 \%(n=13)$ had a master's degree. As supplementary post-registration education, approximately $40 \%$ percent of participants $(43 \%, \mathrm{n}=96)$ had completed a specialised anaesthesia/perioperative nursing programme. The majority of anaesthesia nurses $(75 \%, \mathrm{n}$ =167) participated in occasional continuing education such as seminars or conference at least once a year.

\subsection{Self-assessed level of anaesthesia nursing compe- tence}

The overall mean of anaesthesia nursing competence was 87.5 (SD = 9.0) (see Table 2). About $2 \%$ of anaesthesia nurses assessed their overall competence as between 50-59.9, $3 \%$ as $60-69.9,13 \%$ as $70-79.9,35 \%$ as $80-89.9$, and $47 \%$ as over 90 . The anaesthesia nurses reported that they were most competent in the domain of collaboration within patient care $(\mathrm{M}=92.1, \mathrm{SD}=7.7)$. The domain with the least competence was reported as knowledge of anaesthesia patient care $(\mathrm{M}=$ 79.0, $\mathrm{SD}=14.7$ ).

\subsection{Factors associated with the level of anaesthesia nurs- ing competence}

The overall competence of anaesthesia nurses was associated positively with three background factors: age, length of work experience in anaesthesia nursing, and completion of specialised anaesthesia nursing education. In this study, gender, educational degree level, continuing education (e.g. seminar/conference), and the role of perioperative nurses did not affect the level of anaesthesia nursing competence.

There was a positive, moderate correlation between the overall competence in anaesthesia nursing and age $(\mathrm{r}=.31, \mathrm{n}=$ $220, p<.001)$. There was a significant effect of the length of work experience on the overall competence in anaesthesia nursing $(\mathrm{F}(3,218)=8.09, p<.001)$. The level of anaesthesia nursing competence was compared to the length of work experience (under 2 years, 2-4.9 years, 5-9.9 years, and over 10 years) by using the Tukey HSD test. Anaesthesia nurses with under two years' work experience $(\mathrm{M}=75.9, \mathrm{SD}=11.8)$ self-assessed their anaesthesia nursing competence as being significantly lower than those of nurses who had over two years' work experience. The mean score for the 2-4.9 years $(\mathrm{M}=83.8, \mathrm{SD}=8.6$ ) was significantly lower than that over 10 years $(\mathrm{M}=89.8, \mathrm{SD}=7.5)$ but did not significantly differ from the 5-9.9 years $(M=87.6, S D=7.4)$. Additionally, the mean score for the 5-9.9 years did not significantly differ from that over 10 years (see Table 3 ). In addition, the nurses with specialised anaesthesia nursing education self-assessed their anaesthesia nursing competence as being significantly higher than those without specialised education $(t(220)=$ $3.78, p<.001$ ) (see Table 4).

Table 1. Sample characteristics

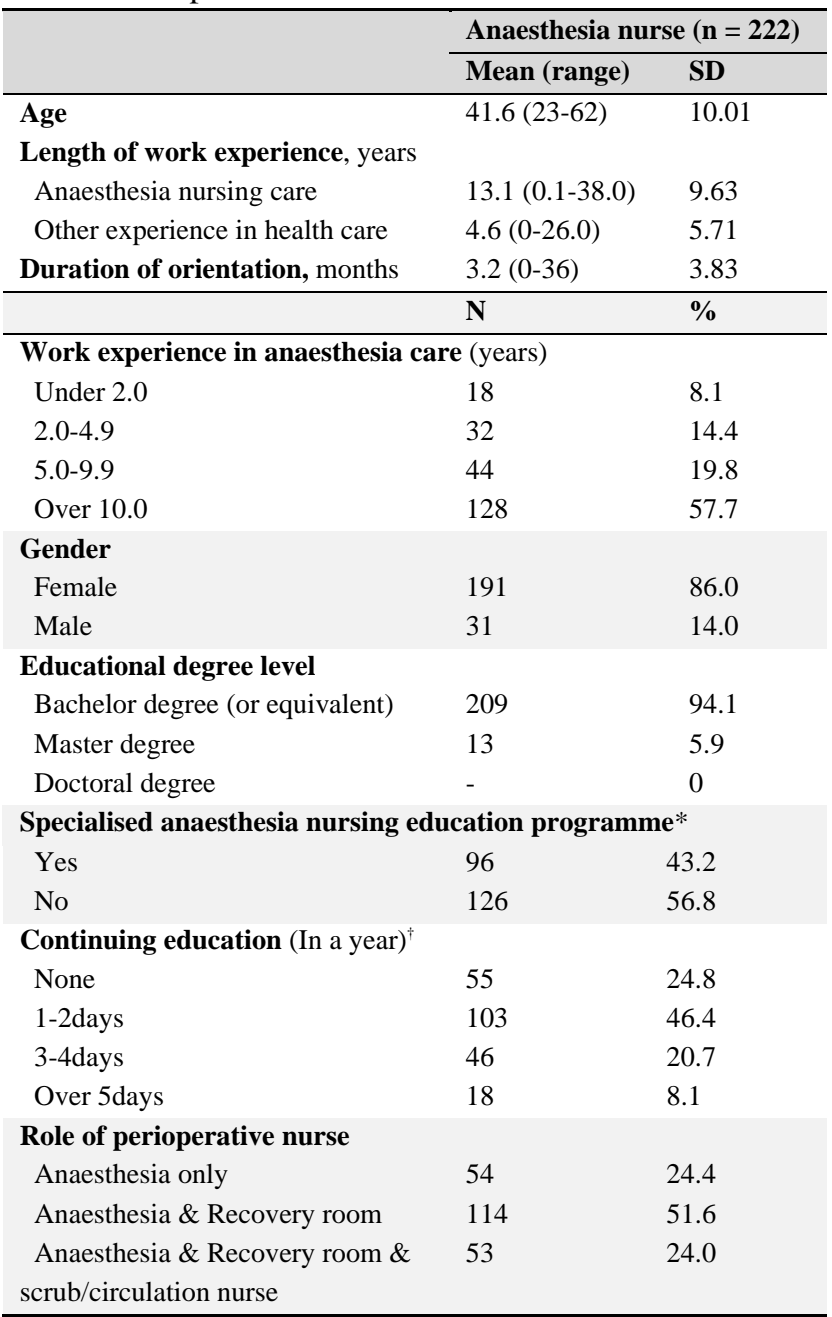

${ }^{*}$ : Post-registration nurse education for anaesthesia care. Duration 1-2 years. 30-60 ECTS (European Credit Transfer and Accumulation System) $\dagger$ : Occasional education such as seminars or conferences

The length of work experience and completion of specialised anaesthesia nursing education were independently associated with overall competence in anaesthesia nursing (see Table 5). In total, these two determinants explained $12.2 \%$ of the variance in anaesthesia nursing competence $\left(R^{2}=0.12\right.$, Model $\mathrm{F}$ $(2,217)=15.14, p<.001)$. 
Table 2. Anaesthesia nursing competence (VAS) of anaesthesia nurses $(\mathrm{n}=222)$

\begin{tabular}{|c|c|c|}
\hline Subscale \& Abbreviated item & Mean & SD \\
\hline Ethics of anaesthesia care & 84.4 & 11.2 \\
\hline 1. Supporting a patient's decision-making & 79.3 & 18.0 \\
\hline 2. Providing information to a patient & 84.2 & 13.7 \\
\hline 3. Advocating for the patient's safety & 85.2 & 14.6 \\
\hline 4. Protecting the patient's privacy & 87.7 & 12.2 \\
\hline 5. Empowering the patient & 85.6 & 14.1 \\
\hline Patient risk care & 82.8 & 12.5 \\
\hline 6. Anticipating the patient's risk potentiality & 84.1 & 13.8 \\
\hline 7. Identifying patient's acute adverse event & 82.8 & 13.4 \\
\hline 8. Assessing how severe an acute adverse event is in a patient & 79.4 & 14.8 \\
\hline 9. Prioritizing actions immediately & 83.1 & 14.2 \\
\hline 10. Following up the patient's condition & 84.7 & 13.9 \\
\hline Patient engagement with technology & 90.3 & 9.0 \\
\hline 11. Checking anaesthesia-machines/technologies required for a patient & 91.7 & 10.4 \\
\hline 12. Identifying the patient's needs through monitoring & 90.9 & 9.1 \\
\hline 13. Seeing the patient as a human being, not just as a part of technology & 91.0 & 11.7 \\
\hline 14. Using a technical equipment to meet the patient's needs & 89.3 & 10.9 \\
\hline 15. Checking the accuracy of documented patient data & 88.1 & 14.6 \\
\hline Collaboration within patient care & 92.1 & 7.7 \\
\hline 16. Doing check-list with a patient & 89.9 & 12.6 \\
\hline 17. Seeking assistance from your anaesthesia colleagues & 94.2 & 8.0 \\
\hline 18. Communicating professionally with an anaesthesiologist & 93.6 & 7.4 \\
\hline 19. Sharing patient's information with OR team & 91.9 & 9.4 \\
\hline 20. Coordinating patient's care with PACU team & 90.5 & 12.6 \\
\hline Anaesthesia patient care with medication & 90.6 & 8.8 \\
\hline 21. Planning patient's anaesthesiological medication needs & 88.6 & 11.8 \\
\hline 22. Assessing patient's needs for medication & 89.2 & 9.9 \\
\hline 23. Administrating anaesthesiological medication safely for patient & 92.5 & 8.6 \\
\hline 24. Evaluating anaesthesiological medication's effectiveness & 90.0 & 10.1 \\
\hline 25. Documentation of medication in the correct manner & 92.7 & 9.1 \\
\hline Peri-anaesthesia nursing intervention & 90.9 & 8.8 \\
\hline 26. Relieving patient's anxiety related to anaesthesia & 88.8 & 12.0 \\
\hline 27. Maintaining patient's breathing/ventilating & 91.7 & 9.5 \\
\hline 28. Maintaining patient's blood circulation & 91.8 & 9.5 \\
\hline 29. Maintaining patient's body temperature & 90.0 & 11.7 \\
\hline 30. Maintaining patient's position & 88.3 & 12.6 \\
\hline 31. Maintaining patient's depth of anaesthesia & 91.3 & 10.5 \\
\hline 32. Maintaining patient's neuromuscular relaxation & 91.8 & 9.6 \\
\hline 33. Relieving patient's pain & 92.4 & 8.3 \\
\hline 34. Relieving patient's nausea and vomiting & 91.9 & 9.2 \\
\hline Knowledge of anaesthesia patient care & 79.0 & 14.7 \\
\hline 35. Knowledge of different types of anaesthesia techniques & 87.9 & 11.4 \\
\hline 36. Knowledge of anatomy relevant to anaesthesia techniques & 81.8 & 15.4 \\
\hline 37. Knowledge of difficult airway management & 83.7 & 15.7 \\
\hline 38. Knowledge of legislation relevant to anaesthesia & 68.1 & 23.3 \\
\hline 39. Knowledge of economic efficiency in anaesthesia care & 73.1 & 21.4 \\
\hline Overall competence & 87.5 & 9.0 \\
\hline
\end{tabular}


Table 3. Anaesthesia nursing competence (VAS) by years of work experience $(\mathrm{n}=222)$

\begin{tabular}{|c|c|c|c|c|c|c|}
\hline \multirow[b]{2}{*}{ Domains } & \multicolumn{6}{|c|}{ Group (mean, SD) by years of work experience } \\
\hline & $\begin{array}{l}\text { Under } 2.0 \\
(n=18)\end{array}$ & $\begin{array}{l}2.0-4.9 \\
(n=32)\end{array}$ & $\begin{array}{l}5.0-9.9 \\
(n=44)\end{array}$ & $\begin{array}{l}\text { Over } 10 \\
(n=128)\end{array}$ & $\mathbf{F}$ & $p$-value ${ }^{\dagger}$ \\
\hline Ethics of anaesthesia care & $77.3(13.3)$ & $79.86(12.1)$ & $83.5(11.4)$ & $86.9(10.1)$ & 6.67 & $<.001^{* * *}$ \\
\hline Patient risk care & $67.3(17.3)$ & $76.98(11.5)$ & $82.7(13.1)$ & $86.5(9.2)$ & 19.09 & $<.001 * * *$ \\
\hline Patient engagement with technology & $80.1(10.4)$ & $87.51(8.9)$ & 90.7 (8.9) & $92.2(7.8)$ & 11.63 & $<.001^{* * *}$ \\
\hline Collaboration within patient care & $84.2(11.0)$ & $91.35(7.1)$ & $91.8(6.9)$ & $93.4(6.9)$ & 8.30 & $<.001^{* * *}$ \\
\hline Anaesthesia patient care with medication & $79.6(12.5)$ & $89.26(7.7)$ & $91.0(6.3)$ & $92.4(8.0)$ & 13.29 & $<.001 * * *$ \\
\hline Peri-anaesthesia nursing intervention & $79.0(13.0)$ & $88.46(9.6)$ & $90.9(7.2)$ & $93.2(6.8)$ & 17.61 & $<.001 * * *$ \\
\hline Knowledge of anaesthesia patient care & $65.4(13.0)$ & $69.56(16.7)$ & $81.2(13.4)$ & $82.5(12.7)$ & 14.10 & $<.001^{* * *}$ \\
\hline Overall competence & $75.9(11.8)$ & $83.81(8.6)$ & $87.6(7.4)$ & $89.8(7.5)$ & 18.09 & $<.001^{* * *}$ \\
\hline
\end{tabular}

${ }^{\top}$ One-way ANOVA, ${ }^{*} p<.05,{ }^{* *} p<.01,{ }^{* * *} p<.001$. Post hoc Tukey HSD test: under 2yrs had mean difference with all other $(p<.001)$

Table 4. Anaesthesia nursing competence (VAS) by specialised anaesthesia nursing education $(n=222)$

\begin{tabular}{lllll}
\hline \multirow{2}{*}{ Domains } & \multicolumn{4}{l}{ Group (mean, SD) by completion of specialised anaesthesia nursing education } \\
\cline { 2 - 5 } & Yes (n = 96) & No (n = 125) & $\boldsymbol{t}(\mathbf{d f})$ & $\boldsymbol{p}_{\text {-value }}^{\dagger}$ \\
\hline Ethics of anaesthesia care & $87.4(10.0)$ & $82.1(11.9)$ & $3.50(219)$ & $<.001^{* * *}$ \\
Patient risk care & $85.9(12.0)$ & $80.5(12.3)$ & $3.29(220)$ & $<.001^{* * *}$ \\
Patient engagement with technology & $92.1(8.4)$ & $88.9(9.2)$ & $2.68(218)$ & $.008^{* *}$ \\
Collaboration within patient care & $93.3(7.4)$ & $91.1(7.8)$ & $2.03(219)$ & $.043^{*}$ \\
Anaesthesia patient care with medication & $92.2(8.2)$ & $89.4(9.1)$ & $2.37(219)$ & $.018^{*}$ \\
Peri-anaesthesia nursing intervention & $92.8(8.3)$ & $89.4(8.9)$ & $2.80(220)$ & $.005^{* *}$ \\
Knowledge of anaesthesia patient care & $83.8(13.3)$ & $75.3(14.7)$ & $4.35(217)$ & $<.001^{* * *}$ \\
Overall competence & $89.9(8.4)$ & $85.5(8.9)$ & $3.78(220)$ & $<.001^{* * *}$ \\
\hline
\end{tabular}

${ }^{\top}$ Independent sample $T$-test, ${ }^{*} p<.05,{ }^{* *} p<.01,{ }^{* * *} p<.001$

Table 5. The independent determinants of anaesthesia nursing competence $(n=219)$

\begin{tabular}{llllll}
\hline Determinant of competence- multiple linear model & B & SE & $\boldsymbol{\beta}$ & $\boldsymbol{T}$ & $\boldsymbol{p}_{\text {-value }}^{\dagger}$ \\
\hline Constant & 83.1 & 0.99 & & 83.956 & $<.001^{* * *}$ \\
Work experience in anaesthesia care (year) & 0.26 & 0.06 & 0.27 & 4.035 & $<.001^{* * *}$ \\
Specialised anaesthesia nursing education $(0=$ no, $1=$ yes) & 2.58 & 1.20 & 0.15 & 2.156 & $.032^{*}$ \\
$R^{2}=.122$. Adju- $R^{2}=.114$ Model F $(2.217)=15.146 . p<.0001$ & & & & \\
\hline
\end{tabular}

\section{Discussion}

In this study, the anaesthesia nursing competence of nurses was assessed with the goal of producing knowledge to support competence-based education in general nursing and post-registration nursing education. The overall competence of anaesthesia nurses was considered to be good. They selfassessed that they were most competent in collaboration within patient care and least competent in knowledge of anaesthesia patient care. Anaesthesia nurses who had longer work experience and specialised anaesthesia nursing education self-assessed themselves to have a higher competence.

In this study, the mean of anaesthesia nurses' overall com- petence level using VAS $(0=$ not competent at all, $100=$ excellent) was 88 . Finnish polytechnics have used a grading scale $0-5(0=\text { fail, } 5=\text { excellent })^{[37]}$ where 4 is good and comparable to a VAS score of 80 . In previous research, a score of more than 70 on a $100 \mathrm{~mm}$ VAS ( $0=$ unsatisfactory, $100=$ outstanding) was used as a standard expected for a nurse with independent responsibility for patient care. ${ }^{[21]}$ Based on Finnish polytechnic grading scale and the previous research, scores of 88 as overall levels of anaesthesia nurse competence can be seen as good and assumed to meet the expected level. However, it might be difficult to define an acceptable level for anaesthesia nursing in actual clinical situations. Patients certainly want to be treated with high quality care and 
their anaesthesia procedures to be done flawlessly. ${ }^{[38,39]} \mathrm{Ex}-$ perts who have an excellent level of competence can grasp situations as a whole with a deep understanding and their performance is not fragmented but holistic and thus patient satisfaction can be increased. ${ }^{[38-40]}$ Accordingly, the levels of anaesthesia nurse competence are ultimately expected to be excellent in all the competence domains.

In terms of the levels of individual domains, it is worth mentioning that collaboration within patient care (VAS 92.1) was the domain considered as being the most competent. Several studies have emphasised that collaboration and teamwork should not be underestimated in order to prevent critical errors and to promote quality of care in the operating room environment. ${ }^{[18,26,41,42]}$ Finnish anaesthesia nurses are regarded as providing patient care in close cooperation and co-decision making with their colleagues. The nurses' collaboration within patient care might be the basis for anaesthesiologists being able to take responsibility for two operating rooms at the same time..$^{[9,41]}$ Whereas, knowledge of anaesthesia patient care (VAS 79.0) was self-assessed as being the least competent domain. It is considered that anaesthesia nurses' perception concerning their competence in knowledge did not meet their expectation when compared to other competence domains. In Finland, anaesthesia departments in local hospitals have trained registered nurses to be competent in anaesthesia patient care. ${ }^{[2,8,9]}$ The results indicate that the hospital-based anaesthesia nurse training might not sufficient to develop the knowledge-based competence of nurses. It is necessary to note that there are huge differences in the provision of theoretical studies related to anaesthesia nursing among Finnish polytechnics. ${ }^{[2,28]}$ Therefore, it is recommended for polytechnics to harmonise a minimum coverage of theoretical studies concerning anaesthesia nursing during the general nurse education.

Factors associated with the level of anaesthesia nursing competence were the length of work experience and completion of specialised anaesthesia nursing education. Many studies have previously described the significance of work experience and additional education in relation to higher selfassessed competence; ${ }^{[43-48]}$ this sample of Finnish anaesthesia nurses confirmed this relationship.

Anaesthesia nurses with under two-years of work experience self-assessed their competence as significantly lower in all domains compared to the more experienced nurses. In particular, the novice nurse group assessed their least competence domain as patient risk care (VAS 67) and knowledge of anaesthesia patient care (VAS 65). Novice nurses may have few opportunities to be exposed to critical situations because emergencies are prevented by detecting precursors

Published by Sciedu Press before acute adverse events arise. ${ }^{[39,49]}$ Therefore, novice nurses need regular opportunities to practice developing their competence in critical situation. Training in a simulated environment can be one option to improve and ensure competence regarding patient risk care. ${ }^{[21,49]}$

Additionally, education in specialised anaesthesia nursing was identified as a factor related to higher anaesthesia nursing competence. In this study, $43 \%$ of anaesthesia nurses $(\mathrm{n}=96)$ who completed post-registration specialised nurse programmes (30-60ECTS) had higher levels of anaesthesia nursing competence across all competence domains than those without specialised education. The domains of the ethics of anaesthesia care, patient risk care, and knowledge of anaesthesia patient care were especially reported as being significantly higher than those with no specialised education. It should be noted that these three domains were the domains of least competence as assessed by the nurse group with under two-years of work experience. This might indicate that such post-registration education can have a key role in supporting and developing such competence domains; these domains require considerable time and resources from the anaesthesia practice of each hospital. ${ }^{[2,9]}$

Higher education enhances competence through both theoretical and clinical knowledge ${ }^{[30,47,48]}$ and better educated nurses have advanced skills as regards clinical judgement and problem solving. ${ }^{[43,50]}$ Globally, nurse anaesthetists who are specially educated in anaesthesia care contribute to anaesthesia nursing practice in a team with the anaesthesiologists. ${ }^{[2,6,51]}$ Some specialised anaesthesia nursing education programmes in the Nordic countries and USA have granted a Master degree. ${ }^{[2,5,6]}$ Unlike these countries, specialised anaesthesia nurse education is optional in Finland. ${ }^{[2,8,9]}$ Most of the head anaesthesiologists and head nurses (87\%) in Finland reported that the current general nurse education for anaesthesia nurses is not sufficient to allow them to perform anaesthesia care immediately after graduation. ${ }^{[2,8,9]}$ Moreover, each anaesthesia department in the hospital has had to invest a considerable amount of time in the training of newly graduated nurses. ${ }^{[2,9]}$ In order to solve this difficulty and provide equivalent anaesthesia care nationally and internationally, development of a specialised anaesthesia nursing education granting a master's degree has been suggested.

\section{Limitations}

This study has some limitations.

1) This was the first study to self-assess anaesthesia nurses' competence in anaesthesia nursing. The developed instrument (AnestComp) was used for the first time in the study. However, the fact that the AnestComp was used for the first time can be a limitation in terms of scale validation. Further 
empirical studies need to be made to ensure the soundness of the scale.

2) The convenience sampling and response rate can be limitations. Sampling from two of the five University hospitals and the $52 \%$ response rate have limitations as to the representativeness of the sample among Finnish anaesthesia nurses. These limitations should be considered when generalising the results. However, these two University hospitals take responsibility for surgical procedures for one third of the Finnish population and endeavours were made to increase the response rate using additional data collection.

3) The study results were based on a self-assessment method. Self-assessment is frequently criticised due to a lack of objectiveness. ${ }^{[6,7,12,28]}$ For self-assessment, participants need to consider their anaesthesia nursing practice in comparison to their own practicing environment. ${ }^{[7,10]}$ Although it was expected that they were realistic in their assessment, some might have under-estimated or over-estimated their competence.

\section{Conclusion}

This study assessed the level of anaesthesia nursing competence, described factors associated with the competence, and discussed fields for competence development and educational needs. Although the overall competence of the anaesthesia nurses was represented as good, there are still areas that require developing as regards anaesthesia nurse competence. In particular, knowledge of anaesthesia patient care and patient risk care should be improved so as to enhance the quality of anaesthesia care and patient safety. In order to do this, it is recommended that the minimum requirements for theoretical and clinical studies for anaesthesia nursing are harmonised between the polytechnics. Hospital-based job orientation and training for anaesthesia nurses needs to pay more attention to competence development in theoretical knowledge and provide regular simulated practice to cope with acute situations. This study suggests that the introduction of a specialised anaesthesia nursing education granting a master's degree could be a solution to meeting the current challenges in anaesthesia nursing in Finland.

As regards further studies, it would be worth assessing anaesthesia nursing competence using samples from different educational levels (e.g. nursing students, registered nurses, and nurse anaesthetists) and different countries in order to identify educational outcomes of each education model. In future studies, multiple assessments such as peer-review, observation, and knowledge-testing together with self-assessment would provide a wider picture of anaesthesia nursing competence in order to support a competence-based education approach.

\section{FUNDING INFORMATION}

This study was financially supported by the Foundation of Finnish Nurse Education, the Finnish Nurses Association, and Helsinki University Hospital.

\section{Conflicts of Interest Disclosure}

No conflict of interest has been declared by the authors.

\section{REFERENCES}

[1] Kajander-Unkuri S, Salminen L, Saarikoski M, et ak. Competence areas of nursing students in Europe. Nurse Educ Today. 2013; 33(6): 625-632. PMid:23462517 https://doi.org/10.1016/j.nedt .2013 .01 .017

[2] Jeon Y, Lahtinen P, Meretoja R, et al. Anaesthesia nursing education in the Nordic countries: Literature review. Nurs Educ Today. 2015; 35(5): 680-688. PMid:25676736 https ://doi.org/10.1016/j . nedt. 2015.01 .015

[3] European Commission: The European Qualification Framework for lifelong learning [Internet]. Official Journal of the European Union (2017/C 189/03) [cited 2018 Oct 25]. Available from: http://eur-lex.europa.eu/legal-content/EN/TXT/ $\mathrm{PDF} /$ ?uri=CELEX : $32017 \mathrm{H0615}$ (01) \& from=EN .

[4] European Commission: Directive (EU) 2019/1 of the European Parliament and of the council [Internet]. Official Journal of the European Union [cited 2019 Jul 25]. Available from: https://eur-lex.europa.eu/legal-content/EN/TX $\mathrm{T} / \mathrm{PDF} /$ ?uri=CELEX : 32019L0001\&f rom=EN .

[5] Meeusen V, van Zundert A, Hoekman J, et al. Composition of the anaesthesia team: a European Survey. Eur J Anaesthesiol. 2010;
27(9): 773-779. PMid:20671555 https : //doi .org/10.1097/EJ A. 0 b013e32833d925b

[6] Jaensson M, Falk-Brynhildsen K, Gillespie BM, et al. Psychometric validation of the perceived perioperative competence scale-revised in the Swedish context. J Perianesth Nurs. 2017; 33(4): 499-511. PMid:30077294 https ://doi.org/10.1016/j.jopan.2016.0 9.012

[7] Kajander-Unkuri S, Suhonen R, Katajisto J, et al. Self-assessed level of graduating nursing students' nursing skills. J Nurs Educ and Pract. 2014; 4(12): 51-64. https ://doi.org/10.5430/jnep.v4n12p5 1

[8] Rosenberg P. Sopiiko skandinaavinen anestesiahoitajamalli Suomeen? Finnanest. 2003; 36(1): 21-23.

[9] Vakkuri A, Niskanen M, Meretoja O, et al. Allocation of tasks between anesthesiologists and anesthesia nurses in Finland. Acta Anaesthesiol Scand. 2006; 50(6): 659-663. PMid:16987358 https : //doi.org/10.1111/j.1399-6576.2006.01036.x

[10] Meretoja R, Leino-Kilpi H, Kaira AM. Comparison of nurse competence in different hospital work environments. J Nurs Manag. 2004; 12(5): 329-336. PMid:15315489 https ://doi.org/10.1111/j . 1365-2834.2004.00422.x 
[11] Axley L. Competency: a concept analysis. Nurs Forum. 2008; 43(4): 214-222. PMid:19076465 https://doi.org/10.1111/j.1744 $-6198.2008 .00115 . x$

[12] Dellai M, Mortari L, Meretoja R. Self-assessment of nursing competencies - validation of the Finnish NCS instrument with Italian nurses. Scand J Caring Sci. 2009; 23(4): 783-791. PMid:19473316 https://doi.org/10.1111/j.1471-6712.2008.00665.x

[13] Tengvall E. Professional competence of perioperative and anesthetist nurse. A questionnaire research to perioperative and anesthetist nurses, anesthesiologists and surgeons (Dissertation). Publication of the University of Eastern Finland. Finland; 2010.

[14] Kane MT. The assessment of professional competence. Eval Health Prof. 1992; 15(2): 163-182. PMid:10119160 https://doi.org/ 10.1177/016327879201500203

[15] Watson R, Stimpson A, Topping A, et al. Clinical competence assessment in nursing: a systematic review of the literature. J Adv Nurs. 2002; 39(5): 421-431. PMid:12175351 https://doi.org/10.1 $046 / j .1365-2648.2002 .02307 . x$

[16] Tavares W, Boet S. On the assessment of paramedic competence: A narrative review with practice implications. Prehosp Disaster Med. 2016; 31(1): 64-73. PMid:26618748 https://doi.org/10.101 7/S1049023X15005166

[17] International Council of Nurses. ICN Framework of competencies for the nurse specialist. Geneva, Switzerland: International Council of Nurses; 2009.

[18] Jeon Y, Lakanmaa RL, Meretoja R, et al. Competence assessment instruments in perianaesthesia nursing care: A scoping review of the literature. J PeriAnesth Nurs. 2017; 32(6): 542-556. PMid:29157761 https://doi.org/10.1016/j.jopan.2016.09.008

[19] Jeon Y, Meretoja R, Vahlberg T, et al. Developing and psychometric testing of the anaesthesia nursing competence scale. J Eval Clin Pract. 2019; 1-13. https://doi.org/10.111/jep.13215

[20] Gaba DM, Howard SK, Flanagan B, et al. Assessment of clinical performance during simulated crises using both technical and behavioural ratings. Anesthesiology. 1998; 89(1): 8-18. PMid:9667288 https://doi.org/10.1097/00000542-199807000-00005

[21] Murray DJ, Boulet JR, Kras JF, et al. A simulation-based acute skills performance assessment for anesthesia training. Anesth Analg. 2005; 101(4): 1127-1134. PMid:16192533 https://doi.org/10.1213/ 01 . ane. $0000169335.88763 .9 a$

[22] Henrichs BM, Avidan MS, Murray DJ, et al. Performance of certified registered nurse anesthetists and anesthesiologists in a simulationbased skills assessment. Anesth Analg. 2009; 108(1): 255-262. PMid:19095860 https://doi.org/10.1213/ane.0b013e3181 $8 \mathrm{e} 3 \mathrm{~d} 58$

[23] Gabriel N. A Study of relationships among three assessment methods for nurse anesthetists (Dissertation). Publication of University of California. United States; 2013.

[24] Robertson ER, Hadi M, Morgan LJ, et al. Oxford NOTECHS II: a modified theatre team non-technical skills scoring system. PLoSOne. 2014; 9(3): e90320. PMid:24594911 https://doi.org/10.137 $1 /$ journal. pone. 0090320

[25] Hedenskog C, Nilsson U, Jaensson M. Swedish-registered nurse anesthetists' evaluation of their professional self. J PeriAnesth Nurs. 2017; 32(2): 106-111. PMid:28343635 https://doi.org/10.1 016/j.jopan. 2015.07.002

[26] Lyk-Jensen HT, Jepsen RM, Spanager L, et al. Assessing nurse anaesthetists' non-technical skills in the operating room. Acta Anaesthesiol Scand. 2014; 58(7): 794-801. PMid:24673620 https://doi.org/ 10.1111/aas. 12315

[27] Wisborg T, Manser T. Assessment of non-technical skills in the operating room - one assessment tool per specialty? Acta Anaesthesiol
Scand. 2014; 58(7): 773-774. PMid:25040951 https ://doi.org/ 10.1111/aas. 12352

[28] Lakanmaa RL, Suominen T, Perttilä J, et al. Graduating nursing students' basic competence in intensive and critical care nursing. J Clin Nurs. 2014; 23(5-6): 645-653. PMid:23786502 https: //doi.org/10.1111/jocn.12244

[29] Lakanmaa RL, Suominen T, Perttilä J, et al. Basic competence in intensive and critical care nursing: development and psychometric testing of a competence scale. J Clin Nurs. 2014; 23(5-6): 799-810. PMid:23331409 https : //doi .org/10.1111/jocn. 12057

[30] Gillespie BM, Chaboyer W, Wallis M, et al. Education and experience make a difference: results of a predictor study. AORN J. 2011; 94(1): 78-90. PMid:21722773 https://doi.org/10.1016/j . ao rn.2010.11.037

[31] Gillespie BM, Polit DF, Hamlin L, et al. Developing a model of competence in the operating theatre: psychometric validation of the perceived perioperative competence Scale-Revised. Int J Nurs Stud. 2012; 49(1): 90-101. PMid:21880313 https ://doi.org/10.101 6/j.ijnurstu.2011.08.001

[32] Gillespie BM, Harbeck EB, Falk-Brynhildsen K, et al. Perceptions of perioperative nursing competence: a cross-country comparison. BMC Nurs. 2018; 17: 12. PMid:29632435 https://doi.org/10 $.1186 / \mathrm{s} 12912-018-0284-0$

[33] Cowan DT, Norman I, Coopamah VP. Competence in nursing practice: a controversial concept - A focused review of literature. Nurs Educ Today. 2005; 25(5): 355-362. PMid:15904996 https://doi.org/10.1016/j.nedt.2005.03.002

[34] WMA: Declaration of Helsinki-Ethical principles for medical research involving human subjects 2013 [Internet]. Ferney-Voltaire: World Medical Association [cited 2018 Jun 13]. Available from: https://www.wma.net/policies-post/wma-declaration -of-helsinki-ethical-principles-for-medical-resea rch-involving-human-subjects/.

[35] Schneider A, Hommel G, Blettner M. Linear regression analysis:part 14 of a series on evaluation of scientific publications. Dtsch Arztebl Int. 2010; 107(44): 776-782.

[36] Moore DS, McCabe GP, Craig BA. Introduction to the practice of statistics. New York: Freeman and Company; 2014.

[37] OPH: Pupil and student assessment [Internet]. Helsinki: Finnish National Agency for Education [cited 2018 Nov 16]. Available from: http://www03.oph.fi/sanasto/alaluokka3_3.asp

[38] Nilsson U, Jaensson M. Anesthetic Nursing: Keep in touch, watch over, and be one step ahead. J Perianesth Nurs. 2016; 31(6): 550-551. PMid:27931710 https://doi.org/10.1016/j . jopan.2016.0 9.005

[39] Larsson J. Monitoring the anaesthetist in the operating theatre - professional competence and patient safety. Anaesthesia. 2017; 72(suppl.1): 76-83. PMid:28044334 https://doi .org/10.1111/ anae. 13743

[40] Benner P. From novice to expert. Am J Nurs. 1982; 82(3): 402 407. PMid:6917683 https://doi.org/10.1097/00000446-1 98282030-00004

[41] Manser T. Teamwork and patient safety in dynamic domains of health care: a review of the literature. Acta Anaesthesiol Scand. 2009; 53(2): 143-151. PMid:19032571 https://doi.org/10.1 $111 / j .1399-6576.2008 .01717 . x$

[42] Larsson J, Holmström IK. How excellent anaesthetists perform in the operating theatre: a qualitative study on non-technical skills. Br J Anaesth. 2013; 110(1): 115-121. PMid:23048067 https: //doi.org/10.1093/bja/aes359

[43] McHugh MD, Lake ET. Understanding clinical expertise: nurse education, experience, and the hospital context. Res Nurs Health. 2010; 
33(4): 276-287. PMid:20645420 https : //doi .org/10.1002/nu r. 20388

[44] Istomina N, Suominen T, Razbadauskas A, et ak. Competence of nurses and factors associated with it. Medicina (Kaunas) 2011; 47(4): 230-237. https://doi.org/10.3390/medicina47040033

[45] Stobinski J. Competency and work environments among military and civilian perioperative registered nurses: A predictive model (Dissertation). Publication of TUI University, United States; 2011.

[46] Hamström N, Kankkunen P, Suominen T, et al. Short hospital stays and new demands for nurse competencies. Int J Nurs Pract. 2012; 18(5): 501-508. PMid:23009380 https://doi.org/10.1111/j. 1440-172X.2012.02055.x

[47] O'Leary J. Comparison of self-assessed competence and experience among critical care nurses. J Nurs Manag. 2012; 20(5): 607-614. PMid:22823216 https://doi .org/10.1111/j.1365-2834. 20 $12.01394 . \mathrm{x}$
[48] Flinkman M, Leino-Kilpi H, Numminen O, et al. Nurse competence scale: a systematic and psychometric review. J Adv Nurs. 2017; 73(5): 1035-1050. PMid:27731918 https://doi .org/10.1111/ jan. 13183

[49] Liaw SY, Scherpbier A, Rethans JJ, et al. Assessment for simulation learning outcomes: A comparison of knowledge and self-reported confidence with observed clinical performance. Nurs Educ Today. 2012; 32(6): e35-e39. PMid:22064013 https://doi.org/10.101 $6 / j$. nedt.2011.10.006

[50] WHO: WHO Europe anaesthetic nursing curriculum-WHO European strategy for continuing education for nurses and midwives [Internet]. Denmark; World Health Organization [cited 2018 Jun 13]. Available from: https://apps.who.int/iris/bitstream/handle /10665/107518/E81550.pdf?sequence=1\&isAllowed=y .

[51] Søreide E, Kalman S, Åneman A, et al. Shaping the future of Scandinavian anaesthesiology: a position paper by the SSAI. Acta Anaesthesiol Scand. 2010; 54(9): 1062-1070. PMid:20887407 https: //doi.org/10.1111/j.1399-6576.2010.02276.x 